\title{
Turkish Adaptation of the Family Adaptability and Cohesion Scale IV
}

\author{
Turgut Turkdogan (D)*,1 Erdinc Duru ${ }^{1}$ Murat Balkis ${ }^{1}$
}

\author{
${ }^{1}$ Pamukkale University, Department of Psychological Counseling and Guidance, 20020 Denizli, TURKEY
}

\section{ARTICLE HISTORY}

Received: 31 March 2018

Revised: 07 August 2018

Accepted: 27 August 2018

\section{KEYWORDS}

Circumplex model, Family adaptability, Family cohesion, family communication, Family functioning, Family satisfaction.

\begin{abstract}
The aim of this study was to examine the psychometric properties of the Turkish version of Family Adaptability and Cohesion Scale IV (FACES IV) Questionnaire Package, and also to achieve a valid and reliable assessment tool for the further investigations of the Circumplex Model of Marital and Family Systems in Turkish culture. A total of 1613 (65.4\% female, $34.6 \%$ male) university students agreed to participate in the study. The construct validity of the FACES IV was examined with confirmatory factor analysis. Also, the convergent validity, criterion-related validity, internal reliability, and test-retest reliability analyses were examined within the scope of validity and reliability studies. Findings indicate that Turkish form of FACES IV can be used as a valid and reliable scale with sufficient psychometric properties to evaluate the family cohesion, family adaptability, family communication, family satisfaction, and the family functioning as a whole in Turkish culture.
\end{abstract}

\section{INTRODUCTION}

The Circumplex Model of Marital and Family Systems is one of the most famous theoretical models investigating family functioning around the world (Gladding, 2011; Hamilton \& Carr, 2016; Kouneski, 2002; Olson, 2011), and the three prominent dimensions that have significant impacts on the family functioning are named as (a) cohesion, (b) flexibility, and (c) communication in the Circumplex Model (Hamilton \& Carr, 2016; Kouneski, 2002; Olson, Russell, \& Sprenkle, 1983, 1989; Olson, Sprenkle, \& Russell, 1979).

The cohesion is a major dimension affecting family functioning in a healthy manner (Barber \& Buehler, 1996; Beavers \& Hampson, 2000; Doherty \& Hovander, 1990; Epstein, Baldwin, \& Bishop, 1983; Gladding, 2011), and it defines the emotional bonding that family members have to each other (Olson et al., 1979, 1989). On the other hand, the extreme values in the cohesion dimension that named as disengaged / disconnected, or enmeshed / overly connected are accepted as unhealthy dynamics for the family functioning (Gladding, 2011; Hamilton \& Carr, 2016; Olson \& Gorall, 2003; Olson et al., 1989).

CONTACT: Turgut Turkdogan $₫$ tturkdogan20@gmail.com $\mathbf{E}$ Pamukkale University, Department of Psychological Counseling and Guidance, 20020 Denizli / TURKEY 
The flexibility is another major dimension affecting family functioning in a healthy manner (Beavers \& Hampson, 2000; Doherty \& Hovander, 1990; Epstein et al., 1983; Gladding, 2011), and it defines the quality and expression of leadership and organization, role relationships, and relationship rules and negotiations in the family system (Olson \& Gorall, 2006; Olson, 2011). On the other hand, the extreme values in the flexibility dimension that named as rigid/inflexible, or chaotic / overly flexible are accepted as unhealthy dynamics for the family functioning (Gladding, 2011; Hamilton \& Carr, 2016; Olson \& Gorall, 2003; Olson et al., 1989).

The communication is the third dimension affecting family functioning in a healthy manner (Beavers \& Hampson, 2000; Epstein et al., 1983; Hamilton \& Carr, 2016), and it essentially defines the positive communication skills used in family system, such as listening emphatically, paying attention to the subject being discussed, and expressing personal feelings sincerely (Olson \& Gorall, 2003; Olson, 2000, 2011).

The main hypothesis of the Circumplex Model is that balanced level of adaptability and flexibility is the main source of the difference between the healthy and unhealthy functioning families across the family life cycle (Gladding, 2011; Hamilton \& Carr, 2016; Kouneski, 2002; Olson et al., 1979, 1983, 1989). Also, another important hypothesis of the Circumplex Model is that families with a balanced level of adaptability and flexibility will tend to display more positive communication skills compared to families with extreme types of adaptability and flexibility (Hamilton \& Carr, 2016; Kouneski, 2002; Olson et al., 1989).

Although the literature contains many assessment tools evaluating family functioning through similar dimensions [Family Structure Assessment Device (Gulerce, 2007), Beavers Systems Model Self-Report Family Inventory (Beavers \& Hampson, 1990), Family Assessment Measure III (Skinner, Steinhauer, \& Sitarenios, 2000), Family Environment Scale (Moos \& Moos, 2009), Family Relations Scale (Tolan, Gorman-Smith, Huesmann, \& Zelli, 1997), McMaster Family Assessment Device (Epstein et al., 1983), and Systemic Clinical Outcome and Routine Evaluation (Stratton, Bland, Janes, \& Lask, 2010)], almost all studies which investigate the crosscultural validity of the Circumplex Model have been conducted with the Family Adaptability and Cohesion Scale (FACES). Specifically, the curvilinear method that includes the combined assessment of the balanced and unbalanced dimensions of the family functioning is can be regarded as the distinctive feature of FACES IV.

Within this scope, FACES IV is a newly revised self-report scale assessing the levels of cohesion and flexibility dimensions that affect family functioning in the Circumplex Model (Gorall, Tiesel, \& Olson, 2006; Olson, 2011; Olson, Gorall, \& Tiesel, 2007). FACES IV Questionnaire Package includes six scales assessing two balanced dimensions (cohesion and flexibility), and four new unbalanced dimensions (disengaged, enmeshed, rigid, chaotic). Additionally, the package includes two other scales that assess the quality of the communication skills among family members (family communication) and the quality of functioning of the family system (family satisfaction). Although the third version of the scale (FACES III) has been adapted to the Turkish culture (Okman-Fisek, 1990), the previous versions of the FACES (I, II, and III) are able to assess the relationship between two balanced dimensions (cohesion and flexibility) and family satisfaction in a linear way (Olson, 2000). On the other hand, FACES IV is also able to assess the relationship between other unbalanced and extreme dimensions (disengaged, enmeshed, rigid, and chaotic) and family satisfaction in a curvilinear way (Gorall et al., 2006; Olson et al., 2007; Olson, 2011).

In summary, the Circumplex Model studies are conducted in more than 1200 studies in many countries around the world, and also supportive findings have been reached for the major hypotheses of the model (Kouneski, 2002; Olson, 2011). Moreover, the cultural adaptation studies on the last version of the FACES have already been completed in many countries such as Greek 
(Koutra, Triliva, Roumeliotaki, Lionis, \& Vgontzas, 2012), Hungary (Mirnics, Vargha, Toth, \& Bagdy, 2010), Israel (Pirutinsky \& Kor, 2013), Italy (Baiocco, Cacioppo, Laghi, \& Tafa, 2013; Loriedo, Di Nuovo, \& Visani, 2013), Portuguese (Pereira \& Teixeira, 2013), Slovakia (Sebokova, Jurisova, Popelkova, Uhlarikova, \& Zatkova, 2016), Spain (Rivero, Martinez-Pampliega, \& Olson, 2010), and Uruguay (Costa-Ball, Gonzalez-Tornaria, delArca, Masjuan, \& Olson, 2013). Correspondingly, more information about the cross-cultural validity of the model is tried to be reached by means of the data obtained from these adaptation studies. Also, an important reference for the future studies emphasizes the need for new researches, especially in collectivist Asian cultures (Kouneski, 2002; Mirnics et al., 2010).

Therefore, the lack of an assessment tool for investigating the major hypotheses of such a famous family approach is remarkably referring to an important gap in Turkish literature, and Turkish adaptation of the FACES IV may offer positive contributions to the literature that investigate the family functioning among Asian cultures with respect to the Circumplex Model. Additionally, Turkish adaptation of the FACES IV may offer positive contributions to the intervention studies aiming to increase the family functioning based on the Circumplex Model among Turkish families. Consequently, the aim of this study was to examine the psychometric properties of the Turkish version of Family Adaptability and Cohesion Scale IV Questionnaire Package (FACES IV), and also to achieve a valid and reliable assessment tool for the future investigations of the Circumplex Model of Marital and Family Systems in Turkish culture.

\section{METHOD}

\subsection{Sample}

The research population consists of 53,063 university students who were studying at different faculties of Pamukkale University in the fall semester of 2016-2017 academic year. The data were collected from 1613 (65.4\% female, 34.6\% male) university students chosen with random cluster sampling method, and the sample consists of Faculty of Education, Faculty of Health Sciences, Faculty of Science and Letters, Vocational High School of Child Care and Youth Services, and Vocational High School of Technical Sciences. In this sense, a representative number of a sample has been reached for the population with a $2.5 \%$ margin of error and $95 \%$ confidence level (Krejcie \& Morgan, 1970). The mean age was $20.79(S D=3.70)$. Also, a subsample of 97 students chosen with convenience sampling method participated in the study of convergent validity. Besides, a sub-sample of 129 students chosen with convenience sampling method participated in the study of test-retest reliability within a three-weeks interval.

\subsection{Instruments}

Family Adaptability and Cohesion Scale IV Questionnaire Package (FACES IV): FACES IV is an individual self-report scale assessing the levels of cohesion and flexibility dimensions that affecting family functioning in the Circumplex Model (Gorall et al., 2006; Olson et al., 2007; Olson, 2011). The three sub-scales that comprise the family cohesion are called as balanced cohesion (e.g., Family members are supportive of each other during difficult times), enmeshed (e.g., We spend too much time together), and disengaged (e.g., Family members seem to avoid contact with each other when at home). The other three sub-scales that comprise the family flexibility are called as balanced flexibility (e.g. Our family tries new ways of dealing with problems), rigid (e.g., There are strict consequences for breaking the rules in our family), and chaotic (e.g., We never seem to get organized in our family). Each of the sub-scales consists of seven items, and the items are evaluated with 5-point Likert scale. Cronbach-alpha coefficient was .89 for the balanced cohesion dimension, .87 for the disengaged dimension, and .77 for the enmeshed dimension. .84 for the balanced flexibility dimension, .82 for the rigid dimension, and .86 for the chaotic dimension in the original study (Olson, 2011). The measurement produces a circular ratio by dividing the balanced dimensions into extreme dimensions: Cohesion 
Ratio $=[$ Balanced Cohesion $] /[($ Disengaged + Enmeshed $) / 2] ;$ Flexibility Ratio $=[$ Balanced Flexibility $] /[($ Rigid + Chaotic $) / 2] ;$ Circumplex Total Ratio $=[($ Cohesion Ratio + Flexibility Ratio) / 2]. Therefore, the higher level of circumplex total ratio refers more balanced family system according to this formulation (Olson, 2011).

Additionally, the quality of the communication skills between family members is measured with the family communication scale (e.g., Family members can calmly discuss problems with each other), and the quality of functioning of the family system is measured with the family satisfaction scale (e.g., How satisfied are you with your family's ability to cope with stress?). Each of these two scales consists of ten items, and the items are also evaluated with 5-point Likert scale. Cronbach-alpha coefficient was .90 for the family communication scale, and .92 for the family satisfaction scale (Olson et al., 2007). The high scores on these scales, reveal the quality of the communication and satisfaction in family system.

The Multidimensional Scale of Perceived Social Support (MSPSS): The scale was developed by Zimet, Dahlem, Zimet \& Farley (1988), and the Turkish adaptation of it was carried out by Eker, Arkar, \&Yaldız (2001). The scale aims to measure the level of support that individuals perceive from social resources in their lives, and the items are evaluated with 7-point Likert scale. The perceived family support sub-scale was used for the convergent validity within the scope of this study, and Cronbach-alpha coefficient was reported as .85 for the family support in the original study (Zimet et al., 1988).

Personal Information Form: This form includes the socio-demographic information of the participants such as gender, age, current marital status of the parents (married or divorced), educational level of the parents, income level of the family, number of children in family, and the family type [nuclear family, extended family, single-parent family, and parentless family (the siblings living together without their parents after divorce or any other reason, etc.)].

\subsection{Procedure}

After obtaining the legal and ethical permissions for the study, data were collected during the fall semester of the 2016-2017 academic year. Within the translation process, each item in the scale was first translated into Turkish by the three authors of the research individually. Then, three separate individual forms prepared by the researchers were put together to reach a common form that would express the Turkish translation of each item in a correct way. The language validity of the final form was examined by two lecturers who have doctoral degree in the field of English Language and Literature, and in the direction of the feedbacks, the Turkish form has been finalized. After that, a pilot study was carried out with the participants out of the current sample and it was concluded that scale items were adequately clear and understandable as a result of feedbacks from the participants.

\subsection{Data Analyses}

Within the scope of the adaptation study, confirmatory factor analysis (CFA) was used for examining the construct validity of the FACES IV, and maximum likelihood was used for the estimation method. Also, confirmatory factor analysis was performed via AMOS (Analysis of Moment Structures) statistical program. In confirmatory factor analysis, the items with low factor loadings below .30 become candidates for dropping. On the other hand, the items with low loadings may be retained at times to satisfy statistical identification requirements, or to meet the minimal number of items per factor (Hair, Black, Babin, \& Anderson, 2014). With respect to this, we firstly preferred to preserve the poorly performing items in the scale as long as they do not jeopardize the overall fit indices. However, we had to delete some items with low factor loadings when the overall fit indices could not be met. As a matter of fact, dropping 
one or two items from a large battery of items can be tolerated for the construct validity, also the confirmatory test may not be jeopardized (Hair et al., 2014).

The internal consistency reliability of the scale was examined with Cronbach-alpha, average variance extracted (AVE), and composite reliability (CR) analyses. Pearson correlation values were used for the convergent validity. Also, $t$ test and variance analyses were conducted to examine whether the families with disadvantaged socio-demographic characteristics can be distinguished by circumplex total ratio within the scope of criterion-related validity. Additionally, other descriptive statistics such as mean, standard deviation, and skewness were performed via SPSS (Statistical Package for the Social Sciences) statistical program.

\section{FINDINGS}

Preliminary assumptions (sample size, normality, linearity, multicollinearity, singularity, homoscedasticity, independence of the error terms) were checked and met before the analyses. Missing data under 5 percent for an individual case was ignored, and the missing values were imputed by the mean substitution method (Hair et al., 2014; Tabachnick \& Fidell, 2001). The descriptive statistics of the FACES IV scales are presented in Table 1. Pearson correlation coefficients between the FACES IV sub-scales are presented in Table 2.

Table 1. Descriptive Statistics of the FACES IV Scales $(\mathrm{N}=1613)$

\begin{tabular}{llrrrrr}
\hline & \multirow{2}{*}{$N$} & \multirow{2}{*}{ Range } & \multirow{2}{*}{$M$} & \multirow{2}{*}{$S D$} & \multicolumn{2}{c}{ Skewness } \\
& & & & Statistic & $S E$ \\
\hline Cohesion Ratio & 1613 & $.29-5.00$ & 1.91 & .62 & .90 & .06 \\
Flexibility Ratio & 1613 & $.24-5.00$ & 2.29 & 1.01 & .49 & .06 \\
Circumplex Total Ratio & 1613 & $.32-4.69$ & 2.10 & .75 & .35 & .06 \\
Family communication & 1613 & $1.00-5.00$ & 3.76 & .93 & -.78 & .06 \\
Family satisfaction & 1613 & $1.00-5.00$ & 354 & .94 & -.61 & .06 \\
\hline
\end{tabular}

Table 2. Pearson Correlation Coefficients between the FACES IV Sub-Scales $(\mathrm{N}=1613)$

\begin{tabular}{|c|c|c|c|c|c|c|c|c|c|c|}
\hline & 1 & 2 & 3 & 4 & 5 & 6 & 7 & 8 & 9 & 10 \\
\hline $\begin{array}{l}\text { 1. Balanced } \\
\text { cohesion }\end{array}$ & - & & & & & & & & & \\
\hline 2. Disengaged & $-.72 * *$ & - & & & & & & & & \\
\hline 3. Enmeshed & $.31 * *$ & $-.17 * *$ & - & & & & & & & \\
\hline $\begin{array}{l}\text { 4. Balanced } \\
\text { flexibility }\end{array}$ & $.79 * *$ & $-.62 * *$ & $.25^{* *}$ & - & & & & & & \\
\hline 5. Rigid & $-.27 * *$ & $.34 * *$ & $.26^{* *}$ & $-.31 * *$ & - & & & & & \\
\hline 6. Chaotic & $-.65 * *$ & $.69 * *$ & $-.13 * *$ & $-.60 * *$ & $.33 * *$ & - & & & & \\
\hline $\begin{array}{l}\text { 7. Cohesion } \\
\text { Ratio }\end{array}$ & $.66^{* *}$ & $-.74 * *$ & $-.38 * *$ & $.55 * *$ & $-.43 * *$ & $-.58 * *$ & - & & & \\
\hline $\begin{array}{l}\text { 8. Flexibility } \\
\text { Ratio }\end{array}$ & $.64 * *$ & $-.65 * *$ & .01 & $.75^{* *}$ & $-.68 * *$ & $-.75 * *$ & $.65^{* *}$ & - & & \\
\hline $\begin{array}{l}\text { 9. Circumplex } \\
\text { Total Ratio }\end{array}$ & $.71 * *$ & $-.75 * *$ & $-.15 * *$ & $.74 * *$ & $-.64 * *$ & $-.75 * *$ & $.86 * *$ & $.95 * *$ & - & \\
\hline $\begin{array}{l}\text { 10. Family } \\
\text { communication }\end{array}$ & $.74 * *$ & $-.63 * *$ & $.28 * *$ & $.78 * *$ & $-.31 * *$ & $-.57 * *$ & $.53 * *$ & $.66^{* *}$ & $.67 * *$ & - \\
\hline $\begin{array}{l}\text { 11. Family } \\
\text { satisfaction }\end{array}$ & $.72 * *$ & $-.65 * *$ & $.27 * *$ & $.75^{* *}$ & $-.32 * *$ & $-.59 * *$ & $.54 * *$ & $.67 * *$ & $.68 * *$ & $.84 * *$ \\
\hline
\end{tabular}




\subsection{The Construct Validity}

The three-factor model about the family cohesion which includes balanced cohesion, enmeshed, and disengaged dimensions was examined with the confirmatory factor analysis, but the first analysis could not produce good fit indices $\left[\chi^{2}(N=1613)=1231.12, p<.0001 ; \chi^{2} / d f=6.62\right.$; $G F I=.93, A G F I=.91, C F I=.90, R M S E A=.60, S R M R=.078]$. Therefore, after two items (item22 and item34) with very low factor loadings and insignificant explained variance values had been excluded from the enmeshed dimension, the construct validity for family cohesion was successfully confirmed $\left[\chi^{2}(N=1613)=716.96, p<.0001 ; \chi^{2} / d f=4.81 ; G F I=.95, A G F I\right.$ $=.94, C F I=.94, R M S E A=.049, S R M R=.052]$. Also, the results of the modified confirmatory analysis for the family cohesion are presented in Figure 1. Although the factor loadings of the item 10 and item 40 were low in the enmeshed dimension, these two items were kept in the scale because of the significant contributions to the explained variance and also having sufficient fit index of the scale (Hair et al., 2014).
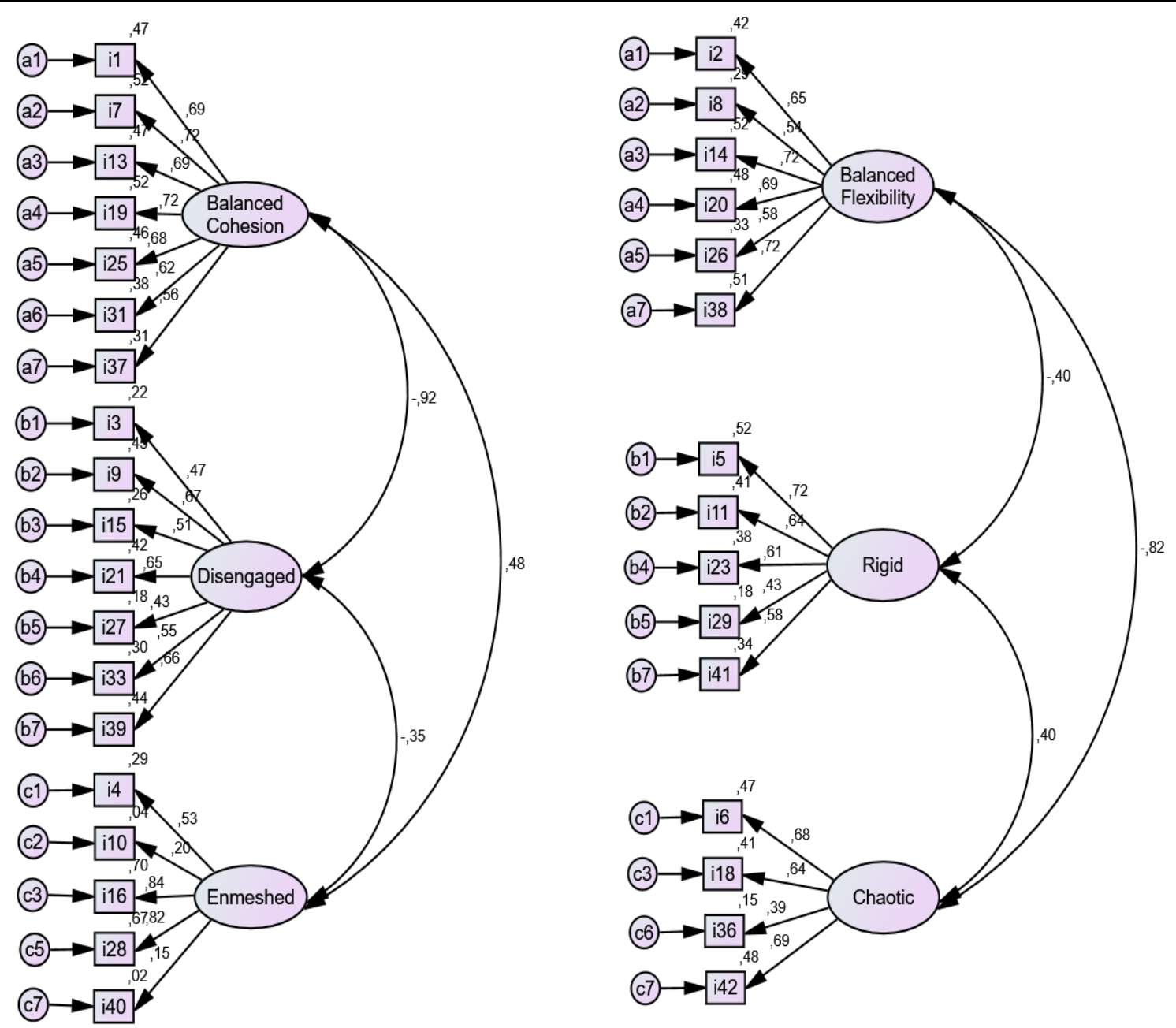

\begin{tabular}{ll}
\hline Note $($ Family Cohesion $): \chi^{2}(N=1613)=716.96, p<$ & Note $($ Family Flexibility $): \chi^{2}(N=1613)=407.32, p<$ \\
$.0001 ; \chi^{2} / d f=4.81 ; G F I=.95, A G F I=.94, C F I=.94$, & $.0001 ; \chi^{2} / d f=4.68 ; G F I=.97, A G F I=.95, C F I=.95$, \\
$R M S E A=.049, S R M R=.052$. & $R M S E A=.048, S R M R=.042$.
\end{tabular}

Figure 1. Modified confirmatory factor analysis results for family cohesion and family flexibility (Standardized solution; $\mathrm{N}=1613$ ). 
The three-factor model about the family flexibility which includes balanced flexibility, rigid, and chaotic dimensions was examined with the confirmatory factor analysis, but the first analysis could not produce acceptable fit indices $\left[\chi^{2}(N=1613)=2049.98, p<.0001 ; \chi^{2} / d f=11.02\right.$; $G F I=.88, A G F I=.85, C F I=.80, R M S E A=.80, S R M R=.092]$. After one item (item32) in the balanced flexibility dimension, two items (item 17 and item35) in the rigid dimension, and three items (item12, item24, and item 30) in the chaotic dimension had been excluded because of the low factor loadings and their tendency to factor under other dimensions beside the factor they belong to, the construct validity for family flexibility was successfully confirmed $\left[\chi^{2}(N=1613)\right.$ $=407.32, p<.0001 ; \chi^{2} / d f=4.68 ; G F I=.97, A G F I=.95, C F I=.95, R M S E A=.048, S R M R=$ $.042]$. The results of the modified confirmatory analysis for the family flexibility are also presented in Figure 1.

One-factor model about the family communication was examined with the confirmatory factor analysis, but the first analysis could not produce good fit indices $\left[\chi^{2}(N=1613)=437.99, p<\right.$ $\left..0001 ; \chi^{2} / d f=12.51 ; G F I=.95, A G F I=.92, C F I=.96, R M S E A=.85, S R M R=.030\right]$. After two items (item45 and item46) had been excluded because of the low factor loadings and their tendency to factor under another independent dimension besides the one-factor model, the construct validity for family communication was successfully confirmed $\left[\chi^{2}(N=1613)=63.5, p\right.$ $\left.<.0001 ; \chi^{2} / d f=3.53 ; G F I=.99, A G F I=.98, C F I=.99, R M S E A=.040, S R M R=.015\right]$. The results of the modified confirmatory analysis for the family communication are presented in Figure 2.
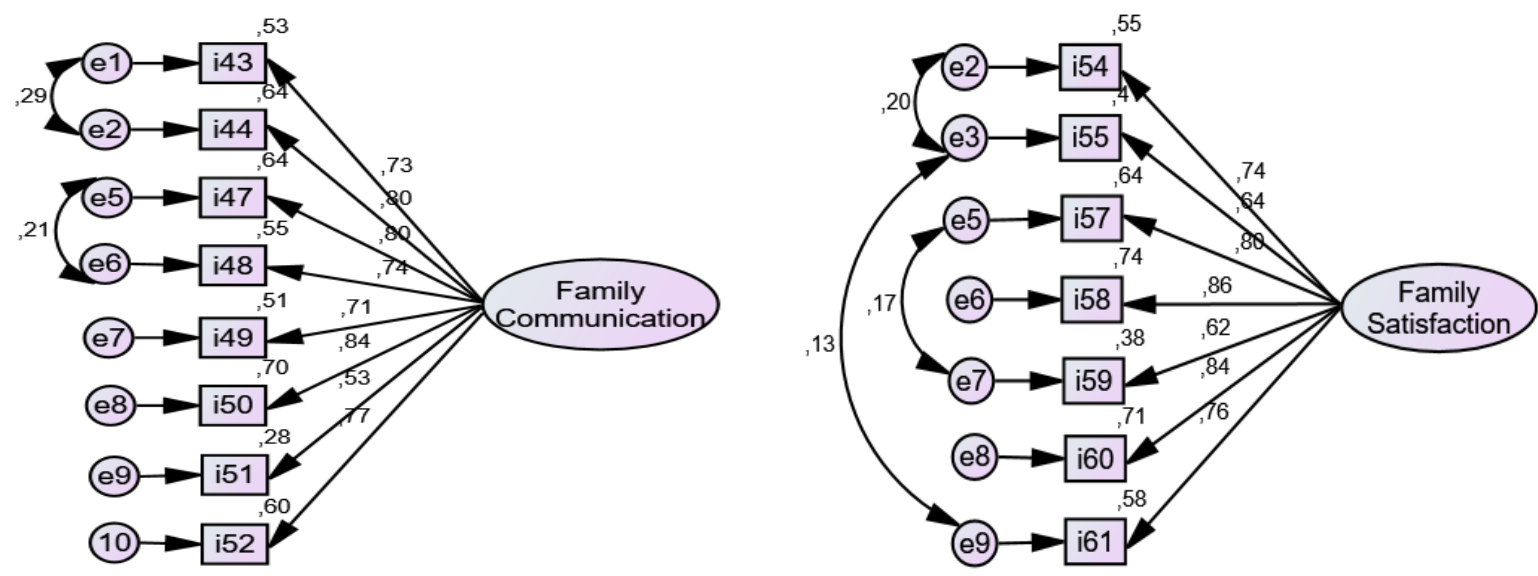

\begin{abstract}
Note (Family Communication $): \chi^{2}(N=1613)=63.57$, $p<.0001 ; \chi^{2} / d f=3.53 ; G F I=.99, A G F I=.98$, $C F I=.99, R M S E A=.040, S R M R=.015$.

Note (Family Satisfaction): $\chi^{2}(N=1613)=53.90, p<$ $.0001 ; \chi^{2} / d f=4.90 ; G F I=.99, A G F I=.98, C F I=.99$, $R M S E A=.049, S R M R=.012$.
\end{abstract}

Figure 2. Modified confirmatory factor analysis results for family communication and family satisfaction (Standardized solution; $\mathrm{N}=1613$ ).

One-factor model about the family satisfaction was examined with the confirmatory factor analysis, but the first analysis could not produce good fit indices $\left[\chi^{2}(N=1613)=805.47, p<.0001\right.$; $\left.\chi^{2} / d f=23.01 ; G F I=.90, A G F I=.84, C F I=.93, R M S E A=.12, S R M R=.042\right]$. After three items (item53, item56, and item62) had been excluded because of the low factor loadings and their tendency to factor under another independent dimension besides the one-factor model, the construct validity for family satisfaction was successfully confirmed $\left[\chi^{2}(N=1613)=53.90, p<\right.$ $\left..0001 ; \chi^{2} / d f=4.90 ; G F I=.99, A G F I=.98, C F I=.99, R M S E A=.049, S R M R=.012\right]$. The results of the modified confirmatory analysis for the family satisfaction are also presented in Figure 2. 


\subsection{The Convergent Validity}

Convergent validity of the FACES IV was examined with the Perceived Social Support Scale among a sub-sample of 97 students chosen with convenience sampling method. According to the findings, positive and strong correlation values were reached between perceived family support and balanced cohesion $\left(r_{(n=97)}=.74, p<.001\right)$, and also balanced flexibility $\left(r_{(n=97)}=.70\right.$, $p<.001)$ dimensions which are defined as the healthy dimensions of the family structure. Moreover, negative correlation values were reached between the level of perceived family support and the disengaged $\left(r_{(n=97)}=-.69, p<.001\right)$, rigid $\left(r_{(n=97)}=-.28, p<.01\right)$, and chaotic $\left(r_{(n=97)}\right.$ $=-.62, p<.001)$ dimensions which are defined as the unhealthy dimensions of the family structure. On the other hand, the positive relationship between perceived family support and enmeshed dimension was not significant $\left(r_{(n=97)}=.11, p>.05\right)$. Also, positive and strong correlation values were found between the perceived family support and the total scores about the cohesion ratio $\left(r_{(n=97)}=.59, p<.001\right)$, flexibility ratio $\left(r_{(n=97)}=.59, p<.001\right)$, and also circumplex total ratio $\left(r_{(n=97)}=.63, p<.001\right)$. Moreover, positive and strong correlation values were found between perceived family support and family communication $(r(n=97)=.65, p<.001)$, and also family satisfaction $\left(r_{(n=97)}=.65, p<.001\right)$.

\subsection{The Criterion-Related Validity}

Marital status of the parents, family type, parents' education level and reading ability, number of children in the family, also income level and perceived economic stress are the remarkable socio-demographic factors affecting family system in the literature (Eccles \& Harold, 1996; Klein \& Forehand, 2000; Mikolajczak, Raes, Avalosse, \& Roskam, 2018; Trent \& South, 1992). Therefore, $t$ test and variance analyses were conducted to examine whether the families with disadvantaged socio-demographic characteristics can be distinguished by circumplex total ratio within the scope of criterion-related validity.

The important finding supporting the criterion-related validity was that circumplex total ratio which indicates the general balance of the family system was significantly lower in the families with disadvantaged socio-demographic characteristics. Also the t test and variance analyses results about the circumplex total ratio and socio-demographics of the family are presented in Table 3. As a matter of fact, circumplex total ratio was significantly lower among the participants from the divorced families $\left(t_{(1611)}=5.40, p<.001\right)$. In addition, circumplex total ratio of the participants who indicated their current family type as parentless-family (the siblings living together without their parents after divorce or any other reason, etc.) was significantly lower than of all groups with the other family types $\left(F_{(3-1609)}=9.03, p<.001\right)$.

Moreover, circumplex total ratio was significantly lower among the participants who have illiterate mothers $(\mathrm{F}(6-1606)=4.77, p<.001)$. However, circumplex total ratio was significantly higher among the participants who have university graduate fathers $\left(F_{(7-1605)}=4.57, p<.001\right)$. Also, circumplex total ratio of the participants from families with five or more children is significantly lower than of all groups which have a less number of children $\left(F_{(4-1608)}=4.84, p<\right.$ $.001)$. Finally, circumplex total ratio of the participants from families that income level is lower than a minimum wage is significantly lower than of all other groups which the family income level is above a minimum wage $\left(F_{(3-1609)}=7.76, p<.001\right)$. 
Table 3. The T Test and Variance Analyses Results about the Circumplex Total Ratio and Socio-Demographics of the Family $(\mathrm{N}=1613)$

\begin{tabular}{|c|c|c|c|c|c|c|}
\hline & Circumplex Total Ratio & $N$ & $M$ & $S D$ & $t / F$ & $p$ \\
\hline \multirow{2}{*}{$\begin{array}{l}\text { Marital status of } \\
\text { the parents }\end{array}$} & Married & 1524 & 2.12 & .74 & \multirow{2}{*}{$5.40 * * *$} & \multirow{2}{*}{.000} \\
\hline & Divorced & 89 & 1.69 & .79 & & \\
\hline \multirow{4}{*}{ Family type } & Nuclear family & 1366 & 2.12 & .74 & \multirow{4}{*}{$9.03 * * *$} & \multirow{4}{*}{.000} \\
\hline & Extended family & 133 & 2.09 & .75 & & \\
\hline & Single-parent family & 83 & 1.98 & .83 & & \\
\hline & Parentless family & 31 & 1.45 & .65 & & \\
\hline \multirow{8}{*}{$\begin{array}{l}\text { Educational level } \\
\text { of the mother }\end{array}$} & Illiterate & 77 & 1.79 & .65 & \multirow{8}{*}{$4.77 * * *$} & \multirow{8}{*}{.000} \\
\hline & Literate & 66 & 1.84 & .69 & & \\
\hline & Primary school & 865 & 2.10 & .74 & & \\
\hline & Middle school & 245 & 2.22 & .75 & & \\
\hline & High school & 270 & 2.13 & .75 & & \\
\hline & College & 25 & 2.07 & .77 & & \\
\hline & University & 65 & 2.13 & .81 & & \\
\hline & Master/ Doctorate & - & - & - & & \\
\hline \multirow{8}{*}{$\begin{array}{l}\text { Educational level } \\
\text { of the father }\end{array}$} & Illiterate & 7 & 1.63 & .52 & \multirow{8}{*}{$4.57 * * *$} & \multirow{8}{*}{.000} \\
\hline & Literate & 34 & 1.77 & .70 & & \\
\hline & Primary school & 620 & 2.04 & .71 & & \\
\hline & Middle school & 307 & 2.13 & .75 & & \\
\hline & High school & 386 & 2.10 & .72 & & \\
\hline & College & 57 & 2.08 & .81 & & \\
\hline & University & 195 & 2.31 & .83 & & \\
\hline & Master/ Doctorate & 7 & 2.42 & .81 & & \\
\hline \multirow{5}{*}{$\begin{array}{l}\text { Number of } \\
\text { children in family }\end{array}$} & Only child & 83 & 2.09 & .73 & \multirow{5}{*}{$4.84 * *$} & \multirow{5}{*}{.001} \\
\hline & Two children & 772 & 2.16 & .77 & & \\
\hline & Three children & 454 & 2.08 & .73 & & \\
\hline & Four Children & 164 & 2.06 & .76 & & \\
\hline & Five or more children & 140 & 1.88 & .61 & & \\
\hline \multirow{4}{*}{$\begin{array}{l}\text { Income level } \\
\text { of the family }\end{array}$} & Under a minimum wage & 435 & 1.96 & .73 & \multirow{4}{*}{$7.76 * * *$} & \multirow{4}{*}{.000} \\
\hline & $\begin{array}{l}\text { Between one or } \\
\text { two minimum wages }\end{array}$ & 802 & 2.14 & .75 & & \\
\hline & $\begin{array}{l}\text { Between two or } \\
\text { three minimum wages }\end{array}$ & 276 & 2.19 & .75 & & \\
\hline & $\begin{array}{l}\text { Three or more } \\
\text { minimum wages }\end{array}$ & 100 & 2.17 & .75 & & \\
\hline
\end{tabular}

\subsection{The Internal Reliability}

The internal consistency reliability of the scale was examined with Cronbach-alpha, average variance extracted, and composite reliability analyses. Also, the values are presented in Table 4. The Cronbach-alpha coefficients ranged between .65 and .91 , the average variance extracted coefficients ranged between .33 and .57 , and the composite reliability coefficients ranged between .66 and .90 for the FACES IV sub-scales. Actually, the values with .60 to .70 are deemed the lower limit of acceptability for the Cronbach-alpha and composite reliability analyses, and the lower limit of the average variance extracted is deemed as .50 (Hair, et al. 2014). 
Table 4. Cronbach-alpha ( $\alpha$ ), Average Variance Extracted (AVE), and Composite Reliability Coefficients for the Internal Reliability

\begin{tabular}{llll}
\hline & $\alpha$ & $A V E$ & $C R$ \\
\hline Balanced cohesion & .85 & .45 & .85 \\
Disengaged & .77 & .33 & .77 \\
Enmeshed & .65 & .34 & .66 \\
Balanced flexibility & .82 & .43 & .82 \\
Rigid & .73 & .36 & .74 \\
Chaotic & .69 & .38 & .70 \\
Family communication & .91 & .48 & .89 \\
Family satisfaction & .91 & .57 & .90 \\
\hline
\end{tabular}

Accordingly, the coefficients for the Cronbach-alpha and composite reliability were emerged at an acceptable level in this study, but coefficients for the average variance extracted were emerged at a low level. On the other hand, in such cases that the average variance extracted is less than .50, but the composite reliability is higher than .60 the convergent validity of the construct may still be deemed adequate (Fornell \& Larcker, 1981).

\subsection{The Test-Retest Reliability}

The stability coefficient of the scale was examined with test-retest method within a three-weeks interval among a sub-sample of 129 students chosen with convenience sampling method. The test-retest coefficient was .85 for the balanced cohesion dimension, .81 for the disengaged dimension, and .71 for the enmeshed dimension. Also, test-retest coefficient was .81 for the balanced flexibility dimension, .76 for the rigid dimension, and .74 for the chaotic dimension. Finally, the test-retest coefficient was .84 for the family communication, and .86 for the family satisfaction. To sum up, the test-retest coefficients of the sub-scales ranged between .71 and 86 for the FACES IV sub-scales.

\section{DISCUSSION AND CONCLUSION}

The current study aimed to examine the psychometric properties of the Turkish version of Family Adaptability and Cohesion Scale IV Questionnaire Package, and also to achieve a valid and reliable assessment tool for the future investigations of the Circumplex Model of Marital and Family Systems in Turkish culture. Also, an important encouragement for the study was the suggestion that highlights the need for new studies investigating the major hypotheses of the Circumplex Model in collectivist Asian cultures (Kouneski, 2002; Mirnics et al., 2010).

The adaptation study of the scale was completed with satisfactory psychometric properties. Specifically, it can be said that a very rigorous examination has been carried out for the construct validity of the scale. Although we tried to preserve the original form of the scale as a whole, the confirmatory factor analyses produced serious modification suggestions. On the other hand, leaving some items out of assessment because of their low factor loading or their tendency to factor under other dimensions besides the factor they expected to fit is a tolerable modification which is commonly observed in other adaptation studies of the FACES IV (Baiocco et al., 2013; Koutra et al., 2012; Mirnics et al., 2010; Pirutinsky \& Kor, 2013; Rivero, Martinez-Pampliega, \& Olson, 2010). Eventually, we have preserved the original form of the scale with all items for the future research in order not to ignore the suggestion of the developers of the scale in that way (Gorall et al., 2006; Olson et al., 2007; Olson, 2011).

Supportive findings have been reached for the convergent validity of the scale in regard to the correlations between the perceived family support scale and the sub-scales of FACES IV. The direction of the correlations was positive for the balanced dimensions of the cohesion and flexibility scales whereas the direction of the correlations was negative for the unbalanced dimensions such as disengaged, rigid, and chaotic. However, there was not a negative correlation 
between the enmeshed dimension and perceived family support, although the enmeshed dimension was conceptualized as an unbalanced dimension in the Circumplex Model. In other words, the enmeshed dimension was not perceived as an unhealthy dimension in regard to the perceived family support in Turkish culture. As a matter of fact, the enmeshed dimension may be perceived as a facilitating dimension which positively contributes to family functioning in the cultures that family togetherness is strongly emphasized (Kouneski, 2002).

Within the scope of criterion-related validity, the scale has successfully discriminated the families with disadvantaged socio-demographic characteristics in regard to the circumplex total ratio. According to these findings, being a member of the divorced or the parentless-family, having an illiterate mother, having five or more siblings in the family, and having a family income lower than a minimum wage were significant risk factors for the balance of the family system. Moreover, having a university graduate father was significantly a protective factor.

The internal reliability coefficients of the Cronbach-alpha and composite reliability appeared with advanced values, with the exception of enmeshed and chaotic dimensions. As a matter of fact, there are many research findings that reporting the similar results about the enmeshed and chaotic dimensions in the literature (Koutra et al., 2012; Marsac \& Alderfer, 2011; Olson, 2011; Pereira \& Teixeira, 2013). Also, the Cronbach-alpha and the composite reliability coefficients of the enmeshed and chaotic dimensions were emerged at an acceptable level in this study. However, the average variance extracted values were emerged at low levels for the other subscales. At this juncture, Fornell and Larcker (1981) who are the developers of the average variance extracted actually described AVE coefficient as a conservative measure, and they recommended that the composite reliability may be deemed adequate for the construct validity of the scale. Finally, the test-retest findings within in a three-weeks interval successfully supported the stability reliability for all sub-scales.

Within the scope of the current study, a valid and reliable scale was obtained with sufficient psychometric properties to evaluate the family cohesion, family adaptability, family communication, family satisfaction, and the family functioning as a whole in Turkish culture. It is also expected that this study will enable further researches to generate positive contributions to the literature that investigating the cross-cultural validity of the Circumplex Model of Marital and Family Systems. Additionally, it is expected that this study will enable further intervention studies aiming to increase the family functioning based on the Circumplex Model among Turkish families.

\section{Acknowledge}

The summary of the study was presented with the title of "Turkish adaptation of Family Adaptability and Cohesion Scale IV: Validity and reliability study" at IV ${ }^{\text {th }}$ International Eurasian Educational Research Congress, 11-14 May 2017, Denizli-Turkey.

\section{ORCID}

Turgut Turkdogan (D) https://orcid.org/0000-0001-5440-341X

\section{REFERENCES}

Baiocco, R., Cacioppo, M., Laghi, F., \& Tafa, M. (2013). Factorial and construct validity of FACES IV among Italian adolescents. Journal of Child \& Family Studies, 22, 962-970.

Barber, B. K., \& Buehler, C. (1996). Family cohesion and enmeshment: Different constructs, different effects. Journal of Marriage and the Family, 58, 433-441.

Beavers, R., \& Hampson, B. (1990). Successful families: Assessment and intervention. New York: W. W. Norton. 
Beavers, R., \& Hampson, B. (2000). The Beavers Systems Model of family functioning. Journal of Family Therapy, 22, 128-143.

Costa-Ball, D., Gonzalez-Tornaria, M., delArca, D., Masjuan, N., \& Olson, D. H. (2013). Psychometric properties of FACES IV: Validity study in Uruguayan population. [Abstract]. Ciencias Psicologicas, 7(2), 119-132.

Doherty, W. J., \& Hovander, D. (1990). Why don't family measures of cohesion and control behave the way they're supposed to? American Journal of Family Therapy, 18, 5-18.

Eccles, J. S., \& Harold, R. D. (1996). Family involvement in children's and adolescents' schooling. In A. Booth \& J. F. Dunn (Eds.), Family school links: How do they affect educational outcomes? (pp. 3-34). Mahwah, NJ: Erlbaum.

Eker, D. Arkar, H., \& Yaldız, H. (2001). Factorial structure, validity, and reliability of revised form of the multidimensional scale of perceived social support. Türk Psikiyatri Dergisi, 12(1), 17-25.

Epstein, N., Baldwin, L., \& Bishop, D. (1983). The McMaster family assessment device. Journal of Marital and Family Therapy, 9(2), 171-180.

Epstein, N., Baldwin, L., \& Bishop, D. (1983). The McMaster family assessment device. Journal of Marital and Family Therapy, 9(2), 171-180.

Fornell, C., \& Larcker, D. F. (1981). Evaluating structural equation models with unobservable variables and measurement error. Journal of Marketing Research, 18(1), 39-50.

Gladding, S. T. (2011). Family therapy: History, theory and practice. $\left(5^{\text {th }}\right.$ ed). Upper Saddle River, New Jersey: Pearson Education.

Gorall, T. M., Tiesel, J., \& Olson, D. H. (2006). FACES IV: Development and validation. Minneapolis, MN: Life Innovations.

Gulerce, A. (2007). The transformational family model and the psychological patterns of families in Turkey. Istanbul: Bogazici University Library Cataloguing.

Hair, J. F., Black, W. C., Babin, B. J., \& Anderson, R. E. (2014). Multivariate data analysis. New Jersey, NJ: Pearson Prentice Hall.

Hamilton, E., \& Carr, A. (2016). Systematic review of self-report family assessment measures. Family Process, 55(1), 16-30.

Klein, K., \& Forehand, R. (2000). Family processes as resources for African-American children exposed to a constellation of sociodemographic risk factors. Journal of Clinical Child Psychology, 29(1), 53-65.

Kouneski, E. (2002). Circumplex model and FACES: Review of literature. Twin Cities, MN: University of Minnesota.

Koutra, K., Triliva, S., Roumeliotaki, T., Lionis, C., \& Vgontzas, A. N. (2012). Cross-cultural adaptation and validation of the Greek version of the family adaptability and cohesion evaluation scales IV package (FACES IV Package). Journal of Family Issues, 34(12), 1647-1672.

Krejcie, R.V., \& Morgan, D.W. (1970). Determining sample size for research activities. Educational and Psychological Measurement, 30, 607-610. doi: $\underline{10.1177 / 001316447003000308}$

Loriedo, C., Di Nuovo, S. F., \& Visani, E. (2013). FACES-IV reliability and validity in an adult Italian sample. Retrieved from http://www.buildingrelationships.com/facesiv_studies/italy_facesiv_2013.pdf

Marsac, M. L., \& Alderfer, M. A. (2011). Psychometric properties of the FACES-IV in a pediatric oncology population. Journal of Pediatric Psychology, 36(5), 528-538. 
Mikolajczak, M., Raes, M. E., Avalosse, H., \& Roskam, I. (2018). Exhausted parents: Sociodemographic, child-related, parent-related, parenting and family-functioning correlates of parental burnout. Journal of Child and Family Studies, 27(2), 602-614.

Mirnics, Z., Vargha, A., Toth, M., \& Bagdy, E. (2010). Cross-cultural applicability of FACES IV. Journal of Family Psychotherapy, 21(1), 17-33.

Moos, R., \& Moos, B. (2009). Family environment scale manual (4th ed.). Palo Alto, CA: Consulting Psychology Press.

Okman-Fisek, G. (1990). Family interconnectedness. Graduate seminar. Bogazici University, Department of Educational Sciences, Istanbul.

Olson D. H., \& Gorall D. M. (2006). FACES IV and the circumplex model. Retrieved from https://www.societyofpediatricpsychology.org/sites/default/files/files/3_innovations.pdf

Olson D. H., Gorall D. M., Tiesel J. W. (2007). FACES IV Manual. Minneapolis, MN: Life Innovations.

Olson, D. H. (2000). Circumplex model of marital and family systems. Journal of Family Therapy, 22(2), 144-167.

Olson, D. H. (2011). FACES IV and the circumplex model: Validation study. Journal of Marital and Family Therapy, 7(1), 64-80.

Olson, D. H., McCubbin, H. I., Barnes, H., Larsen, A., Muxen, M., \& Wilson, M. (1989). Families: What makes them work (2nd ed.). Newbury Park, CA: Sage Publications.

Olson, D. H., Russell, C. S., \& Sprenkle, D. H. (1983). Circumplex model of martial and family systems: VI. Theoretical update. Family Process, 22, 69-83.

Olson, D. H., Russell, C. S., \& Sprenkle, D. H. (1989). Circumplex Model: Systemic assessment and treatment of families. New York, NY: Haworth Press.

Olson, D.H., \& Gorall, D. M. (2003). Circumplex model of marital and family systems. In F. Walsh (Ed.) Normal family processes: Growing diversity and complexity (3rd ed., pp. 514-548). New York, NY: Guilford Press.

Olson, D.H., Sprenkle, D.H., \& Russell, C. S. (1979). Circumplex model of marital and family system: I. Cohesion and adaptability dimensions, family types, and clinical applications. Family Process, 18(1), 3-28.

Pereira, M. G., \& Teixeira, R. J. (2013). Portuguese validation of FACES-IV in adult children caregivers facing parental cancer. Contemporary Family Therapy: An International Journal, 35, 478-490.

Pirutinsky, S., \& Kor, A. (2013). Relevance of the circumplex model to family functioning among Orthodox Jews in Israel. The New School Psychology Bulletin, 10(2), 25-38.

Rivero, N., Martinez-Pampliega, A., \& Olson, D. H. (2010). Spanish adaptation of the FACES IV questionnaire: Psychometric characteristics. The Family Journal, 18(3), 288-296.

Sebokova, G., Jurisova, E., Popelkova, M., Uhlarikova, J., \& Zatkova, M. (2016). Factorial validity and reliability of the Slovak version of the F ACES IV in adolescents. [Abstract]. Ceskoslovenska Psychologie, 60(3), 278-289.

Skinner, H., Steinhauer, P., \& Sitarenios, G. (2000). Family assessment measure (FAM) and process model of family functioning. Journal of Family Functioning, 22, 190-210.

Stratton, P., Bland, J., Janes, E., \& Lask, J. (2010). Developing an indicator of family function and a practicable outcome measure for systemic family and couple therapy: The SCORE. Journal of Family Therapy, 32, 232-258.

Tabachnick, B. G., \& Fidell, L. S. (2001). Using multivariate statistics (4th ed.). Boston: Allyn \& Bacon. 
Tolan, P., Gorman-Smith, D., Huesmann, R., \& Zelli, A. (1997). Assessment of family relationship characteristics: A measure to explain risk for antisocial behaviour and depression among urban youth. Psychological Assessment, 9(3), 212-223.

Trent, K., \& South, S. J. (1992). Sociodemographic status, parental background, childhood family structure, and attitudes toward family formation. Journal of Marriage and Family, 54(2), 427-439.

Zimet, G. D., Dahlem, N. W., Zimet, S. G., \& Farley, G. K. (1988). The multidimensional scale of perceived social support. Journal of Personality Assessment, 52(1), 30-41. 